\title{
Comparison of effects of propranolol and practolol on exercise tolerance in angina pectoris ${ }^{1}$
}

\author{
D. J. Coltart \\ From the Cardiac Department, St. Bartholomew's Hospital, London E.C.I
}

Beta-adrenergic blockade has been shown to improve the exercise tolerance of patients with angina pectoris. Propranolol has both beta-adrenergic blocking and local anaesthetic properties which might be responsible for its action, and with the development of practolol, a beta-adrenergic blocking agent without local anaesthetic properties, an assessment of the relative importance of beta-adrenergic blockade and local anaesthetic effect in the amelioration of the symptoms in angina pectoris can be performed.

Six patients with long-standing angina pectoris were exercised on a treadmill to assess the effect of intravenous administration of propranolol $0.15 \mathrm{mg}$. $/ \mathrm{kg}$. body weight, practolol $0.3 \mathrm{mg} . / \mathrm{kg}$. body weight, or a placebo on their exercise tolerance. The same procedure was repeated after oral administration of propranolol $50 \mathrm{mg}$. 8-hourly, practolol $100 \mathrm{mg}$. 8-hourly, or a placebo. The treadmill is a reproducible test of exercise tolerance, providing a situation similar to the normal daily life of the patient.

There was a significant increase in exercise tolerance $(p<0.05)$ in the oral and intravenous studies with both propranolol and practolol. No distinction could be made on the basis of exercise tolerance either between the drugs or their mode of administration.

$A$ beneficial effect on exercise tolerance is observed in angina pectoris from beta-adrenergic blockade. In the doses used the effect of propranolol is not related to its local anaesthetic activity, since a similar response was noticed with practolol. Practolol does not affect the bronchi and may be given to patients with obstructive airways disease, and as it has a relatively slight effect on contractility may be better tolerated in the presence of cardiac failure.

Beta-adrenergic blockade has been shown to improve the exercise tolerance of patients with angina pectoris (Hamer and Sowton, 1966; Grant et al., 1966; Birkett and Chamberlain, 1966). The improvement is thought to be due to a reduction in myocardial oxygen consumption from blockade of sympathetic stimulation. Propranolol has local anaesthetic (or quinidine like) activity which might be responsible for its action but produces symptomatic effect in ischaemic heart disease in doses which only minimally depress the myocardium through this mechanism (Blinks, 1967). The development of practolol (I.C.I. 50,172), a cardioselective beta-adrenergic blocking agent with no local anaesthetic activity (Dunlop and Shanks, 1968), allows an assessment of the relative importance of betaadrenergic blockade and local anaesthetic effect in the amelioration of the symptoms in angina pectoris.

Received 21 May 1970.

1 This study was supported by a grant from I.C.I. Ltd.

\section{Methods}

Six male patients with ages ranging between $4 \mathrm{I}$ and 59, with a mean of $5 \mathrm{I}$, were studied. They all had a clear classical history of angina, the duration of symptoms varying from I to 12 years, with an average of 5 years. Patients were excluded from the study if they had angina at rest or on slight exertion, any evidence of left ventricular failure, or a recent myocardial infarct. All patients were normotensive and the resting electrocardiograms showed evidence of ischaemic heart disease in 4 patients, the remainder being normal. All therapy with the exception of glyceryl trinitrate was withdrawn $\mathbf{7 2}$ hours before the study.

The patients received a detailed explanation of the nature of the investigation and were familiarized with the cardiac laboratory. They were exercised on a motor-driven treadmill with adjustable speed and slope. The severity of exercise was varied according to the effort tolerance of each patient, and the treadmill was stopped as soon as pain occurred. The patients were asked to stop the subsequent tests at the point when they first experienced the same degree of pain. The treadmill speed was adjusted so that, after 
training, angina would be provoked by one and a half to two minutes of walking; if an earlier limit were reached, the exercise would be more strenuous than usually taken; for a later limit the exercise response would approach a steady state and a marginal improvement in exercise tolerance would produce a significantly good result.

Various precautions were taken to control factors which might influence effort tolerance. The patients rested for 15 minutes before each exercise, only a single exercise test being performed in a single day; the time after the previous meal was identical for all experiments, the patient being in a semi-fasting state. The patients were not permitted to smoke for two hours before they walked, and if glyceryl trinitrate had been taken in the same period the test was postponed. Finally, practice walks on the treadmill were repeated until the patient was completely familiar with the technique and free from apprehension.

When effort tolerance had become consistent to within 15 seconds on four tests, the experimental procedure was repeated five minutes after the administration of propranolol $0.15 \mathrm{mg} . / \mathrm{kg}$. body weight, or practolol $0.3 \mathrm{mg}$. $/ \mathrm{kg}$. body weight, or normal saline, intravenously given in a random

- order unknown to the patient. The same procedure was repeated after three days on propranolol $50 \mathrm{mg}$. 8-hourly, practolol roo mg. 8-hourly, or placebo tablets, the exercise test being

performed on the third day with a 3-day lapse of medication between each day.

The significance of the changes was calculated by Student's $t$ test for paired data.

a The electrocardiogram was recorded on a Sanborn direct writing electrocardiograph during the tests, using a modified CR6 lead. Recordings were taken at rest and at every half minute during exercise, and any change was closely followed until the resting pattern returned.

\section{Results}

The results are shown as the per cent change in exercise tolerance with the beta-blocking agent compared with the placebo. Fig. I shows the results of the intravenous study and Fig. 2 the results of the oral study. The administration of the placebo was not followed by more than a slight change in exercise time in any patient.

The changes observed for the intravenous study (Fig. I) ranged from an increase in effort tolerance of 6 to IOI per cent compared with the placebo, with a mean of $64 \cdot 2$ per cent with practolol; and an increase in effort tolerance of 5 to 104 per cent, with a mean of 62.3 per cent with propranolol. The changes observed for the oral study (Fig. 2) ranged rom an increase in effort tolerance of ro to I22 per cent compared with the placebo, with a mean of 52.6 per cent with practolol; ind a decrease of 6 per cent to an increase of II2 per cent, with a mean of 42.3 per cent vith propranolol.

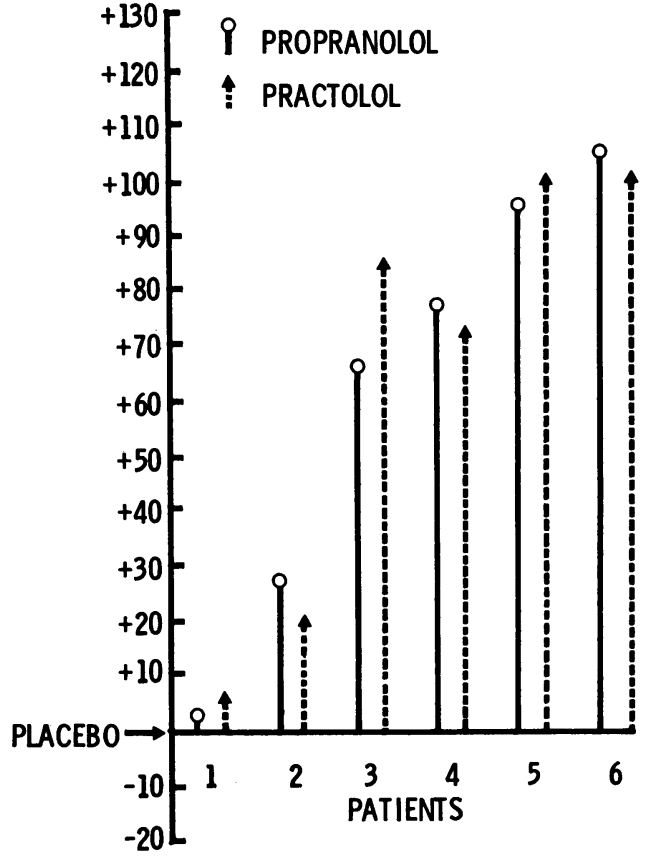

FIG. I Percentage change in exercise tolerance compared with the placebo after intravenous administration of propranolol and practolol.

FIG. 2 Percentage change in exercise tolerance compared with the placebo after oral administration of propranolol and practolol.

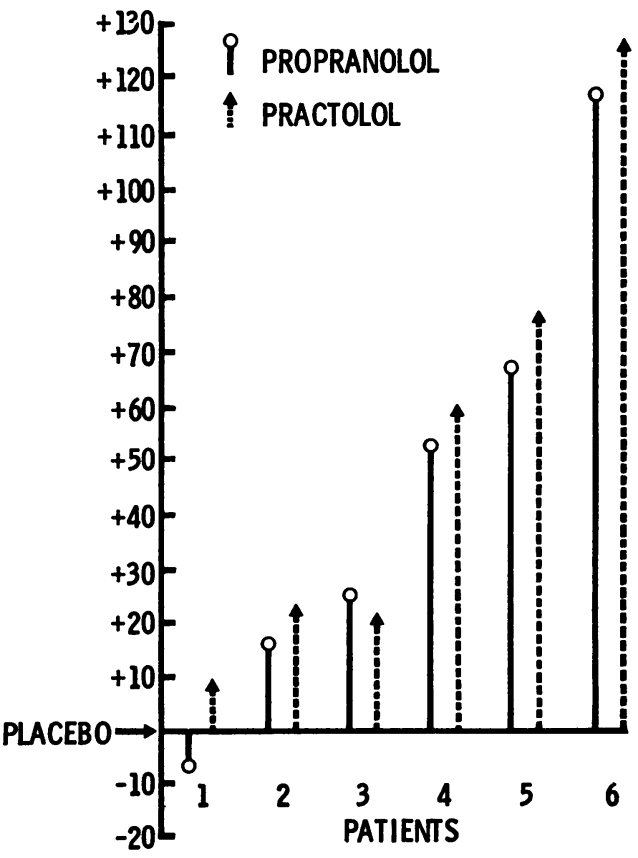


There was a significant increase in exercise tolerance $(p<0.05)$ in the oral and intravenous studies with both propranolol and practolol, with no significant difference in the exercise tolerance either to the mode of administration of the drugs or between the drugs.

Patient 5 has subsequently had a bilateral upper thoracic sympathectomy and has a postoperative exercise tolerance at the 140 per cent level, previously achieving levels of 97 and 70 per cent respectively on the intravenous and oral beta-blockers.

\section{Discussion}

The reproducibility of the exercise load is of greater importance than a rigorously designed double-blind trial in assessing drugs in the treatment of angina pectoris. It is difficult to find a sufficient number of patients with frequent angina whose condition is clinically stable; a high placebo response is a feature of the condition; disability varies from day to day with the level of activity and environmental temperature; and, finally, the number of glyceryl trinitrate tablets used, a common yardstick in trials of this sort, may not adequately reflect changes in effort tolerance. The method described achieves a consistent level of effort tolerance allowing a sensitive comparison of the effect of a drug with that of a placebo. A lengthy 'training' period together with the other precautions mentioned achieves the reproducibility of the exercise load. During the earlier practice tests the degree of effort required to produce pain usually increases, but subsequently the onset of pain provides an accurate and reproducible end-point. The use of walking as the exercise load provides a test situation similar to the normal daily life of the patient.

Practolol was given in a dose twice that of propranolol, because animal experiments (Dunlop and Shanks, 1968) show that this is the equipotent dose to achieve comparable attenuation of sympathetic stimulation with propranolol. Blinks (1967) has shown that propranolol in doses above 0.15 to $0.2 \mathrm{mg} . / \mathrm{kg}$. body weight has a depressing effect on the myocardium.

Though the exercise tolerance was greater after the intravenous therapy than the oral therapy, there was no statistically significant change. Poor absorption of the drugs may be an explanation for this difference. However, Patient I was resistant to improvement from both routes of administration and with both drugs.

In the doses used in this study there is a similarity of beneficial effect on exercise tolerance in angina pectoris with propranolol and practolol. The beneficial effect of propranolol appears to be unrelated to its local anaesthetic properties, since a similar response was noticed with practolol. Practolol, with its cardioselectivity, may be given to patients with obstructive airways disease and may be better tolerated in the presence of cardiac failure (George, Nagle, and Pentecost, 1970).

A similar response to exercise tolerance in angina pectoris (Wilson et al., I969) has been noticed with propranolol and practolol, and further no difference was noticed in that study between the exercise time with saline and with the dextro-isomer of propranolol, which has the same local anaesthetic action as propranolol with negligible beta-adrenergic receptor blocking activity.

The further improvement in exercise tolerance in the sympathectomized patient agrees with the studies of Apthorp, Chamberlain, and Hayward (1964).

It is tempting to postulate that the improvement in exercise tolerance in patients with angina pectoris results from pure betaadrenergic receptor blockade, but any additional benefit that propranolol might have from its local anaesthetic properties in preventing or suppressing arrhythmias has not been fully evaluated.

\section{References}

Apthorp, G. H., Chamberlain, D. A., and Hayward, G. W. (1964). The effects of sympathectomy on the electrocardiogram and effort tolerance in angina pectoris. British Heart fournal, 26, 218.

Birkett, D. A., and Chamberlain, D. A. (1966). Betaadrenergic blockade in angina pectoris: a method of treadmill assessment. British Medical fournal, 2, 500.

Blinks, J. R. (1967). Evaluation of the cardiac effects of several beta adrenergic blocking agents. Annals of the Nerw York Academy of Sciences, 139, 673.

Dunlop, D., and Shanks, R. G. (1968). Selective blockade of adrenoceptive beta receptors in the heart. British fournal of Pharmacology and Chemotherapy, 32, 201.

George, C. F., Nagle, R. E., and Pentecost, B. L. (1970). Practolol in treatment of angina pectoris. A double-blind trial. British Medical fournal, 2, 402.

Grant, R. H. E., Keelan, P., Kernohan, R. J., Leonard, J. C., Nancekievill, L., and Sinclair, K. (1966). Multicenter trial of propranolol in angina pectoris. American fournal of Cardiology, 18, 36r.

Hamer, J., and Sowton, E. (I966). Effects of propranolol on exercise tolerance in angina pectoris. American fournal of Cardiology, 18, 354.

Wilson, A. G., Brooke, O. G., Lloyd, H. J., and Robinson, B. F. (1969). Mechanism of action of beta-adrenergic receptor blocking agents in angina pectoris : comparison of action of propranolol with dexpropranolol and practolol. British Medical fournal, $4,399$. 